\title{
Predictive Controller Design for a Three-Winding Inductive Power Transfer System
}

\author{
Tian-Hua Liu *(D, Muhammad Syahril Mubarok (D) and Zheng-Jun Liu \\ Department of Electrical Engineering, National Taiwan University of Science and Technology, Taipei 106, Taiwan; \\ syahril.elmubarok@gmail.com (M.S.M.); M10607C03@mail.ntust.edu.tw (Z.-J.L.) \\ * Correspondence: Liu@mail.ntust.edu.tw
}

Citation: Liu, T.-H.; Mubarok, M.S.; Liu, Z.-J. Predictive Controller Design for a Three-Winding Inductive Power Transfer System. Energies 2021, 14, 1549. https://doi.org/10.3390/ en14061549

Academic Editor: Dong-Wook Seo

Received: 1 February 2021

Accepted: 8 March 2021

Published: 11 March 2021

Publisher's Note: MDPI stays neutral with regard to jurisdictional claims in published maps and institutional affiliations.

Copyright: (c) 2021 by the authors. Licensee MDPI, Basel, Switzerland. This article is an open access article distributed under the terms and conditions of the Creative Commons Attribution (CC BY) license (https:// creativecommons.org/licenses/by/ $4.0 /)$.

\begin{abstract}
Inductive power transfer (IPT) systems have become more and more popular recently To improve transient responses and load disturbance responses, this paper proposes a predictive controller design for a three-winding inductive power transfer (IPT) system. First, a three-winding IPT is presented. Next, a predictive controller is designed based on augmented variables and a performance index. Finally, a digital signal processor, TMS 320F2808, made by Texas Instrument, is used to execute the predictive control algorithms and to control the switching states of the power devices. An IPT system, with DC $220 \mathrm{~V}$ input, DC $130 \mathrm{~V}$ output, and a rated power of $2 \mathrm{~kW}$, is implemented. A buck converter is used to provide an adjustable output voltage and output current to charge a battery set. Experimental results show that the proposed predictive controllers of the IPT system have better performance than proportional-integral (PI) controllers, including faster transient responses and better load disturbance responses.
\end{abstract}

Keywords: three-winding; coreless; inductive power transfer system; model predictive control; third winding

\section{Introduction}

Inductive power transfer (IPT) systems have been widely used to transfer power without physical contact. The IPT system overcomes many disadvantages of traditional physically contacted power transfer systems that cause sliding wear, contact sparks, and several other dangers caused by dirt and moisture. Several researchers have investigated different aspects of IPT systems. For example, Chen et al. proposed using a third coil to improve misalignment tolerance of IPT systems [1]. Shevchenko et al. investigated compensation topologies in IPT systems [2], and Hao studied an IPT power supply for wireless electric vehicles [3].

Recently, several researchers have focused on advanced controller designs for IPT systems. For example, Li et al. investigated a robust controller for IPT systems to improve the problems of parametric uncertainty, load disturbance, and misalignment [4]. Based on a closed-loop IPT system with a two-degree-of-freedom control structure, good performance can be obtained, even though the mutual inductances vary and load changes. Xia et al. implemented a $\mu$-synthesis control method of an LCL IPT system. The $\mu$-synthesis control method was based on structured singular values [5]. Their experimental results showed that the proposed IPT system could quickly and accurately track the reference voltage. Li et al. studied a two-degree-of-freedom $H^{\infty}$ controller for an IPT system with parameter perturbations [6]. Based on a state-space model, a two-degree-of-freedom $H^{\infty}$ controller, which was very complex, was developed. Nail et al. proposed an optimal static statefeedback controller design for a multivariable IPT system [7]; however, that paper did not demonstrate experimental results.

Predictive controllers present several advantages that make them suitable for motor drives and power electronic applications, including IPT systems. The concepts of predictive controllers are intuitive and easy to understand. They can be applied for different IPT 
systems that include input constraints and nonlinearities. Although the design of predictive controllers requires prediction, a performance index, and optimization, its realization is very simple when a digital signal processor is used [8,9]. To the authors' best knowledge, there are no or only a few researchers who have investigated predictive controller designs for IPT systems. To fill this research gap, a predictive controller design for an IPT system is proposed here. By using the augmented variables, the state equation of an IPT system is easily developed. Next, the predictive controller is designed based on a performance index. Finally, a model-based predictive controller is designed. By using a digital signal processor (DSP), the predictive controllers are implemented, which provide better performance than proportional-integral (PI) controllers, including faster responses and better load disturbance responses. To the authors' best knowledge, the ideas demonstrated in this paper are original and have not been discussed in previously published papers [1-9].

\section{The Three-Winding IPT}

Only a few researchers have focused on the comparison of a two-winding IPT and a three-winding IPT. Chen et al. proposed a three-winding IPT system to improve its misalignment tolerance and efficiency [1]. In reference [1], the authors demonstrate that the third-coil improves the misalignment performance and also affects the characteristics of the compensation circuit. In this paper, a three-winding IPT, shown in Figure 1, is used. This IPT does not use any core. A comparison of a two-winding IPT and a three-winding IPT is not shown in this paper because they have different characteristics. As a result, this paper only focuses on the three-winding IPT. The three-winding IPT provides several advantages. In Figure 1, the third winding of the IPT system provides a high current $i_{1}$, which is over $12 \mathrm{~A}$ from the experimental results in this paper. The major reason is that the third winding is short-circuited when the winding is in resonance. The current $i_{1}$ provides an extra current to the primary winding. However, when the third winding is operated at a frequency that is different from the resonant frequency, the internal impedance is increased, and then the current in the third winding is reduced. In fact, the third winding enhances the flux-linkages in the primary winding compared to an IPT, which does not use a third winding. Moreover, the third winding also provides reactive power, supplies phase angle compensation, and increases the kVA capability in the primary winding, all of which effectively reduces the deterioration of the output power when the IPT has a larger air gap or a misalignment between the primary winding and the secondary winding [10]. It is well known that the third winding of a transformer can be used to compensate for the influence of disturbances of an output load, such as harmonics and a three-phase unbalanced load for a power system. The major reason is that the third winding can stabilize voltages, supply the third harmonic currents to magnetize the transformer core, filter third harmonics from the system, and provide grounding action. The detailed explanations are shown in reference book [10]. In this paper, we use the same concept and use a third winding to provide the reactive power to reduce the deterioration of air gap variations and misalignment between the primary winding and secondary winding of an IPT system.

The main circuit of the three-winding IPT is shown in Figure 2, which includes an $\mathrm{H}$ bridge, three windings, a full-wave rectifier, a DC/DC buck converter, a filtering capacitor, and a resistor. By suitably designing the H-bridge circuit, zero-voltage switching can be obtained since the diode is turned on before the MOSFET turns on. In addition, the primary winding is arranged near the third winding to increase their mutual inductance. The DC/DC buck converter is used to reduce the output voltage so that it matches the load voltage.

Figure $3 a-c$ show the whole AC equivalent circuit of the three windings. Figure $3 a$ shows the equivalent circuit of the primary winding. Figure $3 \mathrm{~b}$ shows the equivalent circuit of the third winding. Figure $3 c$ shows the equivalent circuit of the second winding. In Figure $3 \mathrm{a}-\mathrm{c}, R_{0}$ is the equivalent resistance of the primary winding, $R_{2}$ is the equivalent resistance of the secondary winding, $R_{1}$ is the equivalent resistance of the third winding, $C_{0}$ is the equivalent capacitance of the primary winding, $C_{2}$ is the equivalent capacitance of 
the secondary winding, $C_{1}$ is the equivalent capacitance of the third winding, $C_{L^{\prime}}$ is the AC equivalent capacitance of the filtering capacitance $C_{L}$, and $R_{L^{\prime}}$ is the AC equivalent resistance of the load $R_{L}$.

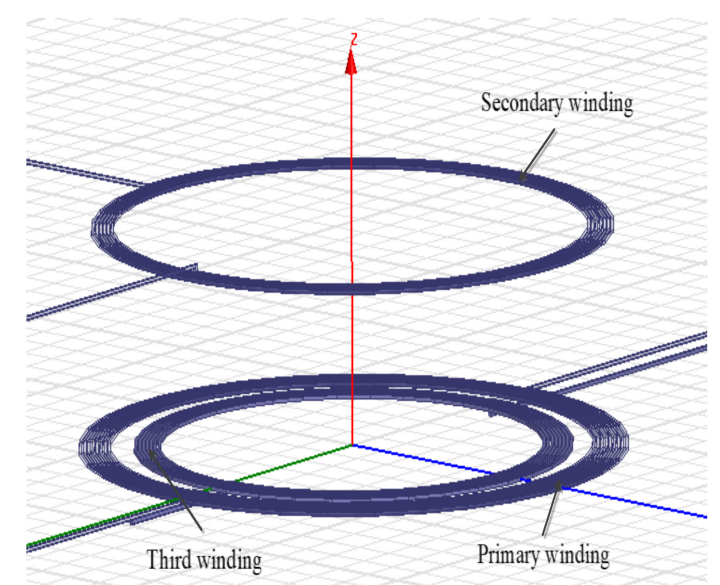

Figure 1. The three-winding inductive power transfer (IPT).

$$
\begin{array}{lccc}
\text { H-bridge } \quad \text { Coupling Windings } & \begin{array}{c}
\text { Full-wave } \\
\text { Rectifier }
\end{array} & \text { Converter } & \text { Load }
\end{array}
$$

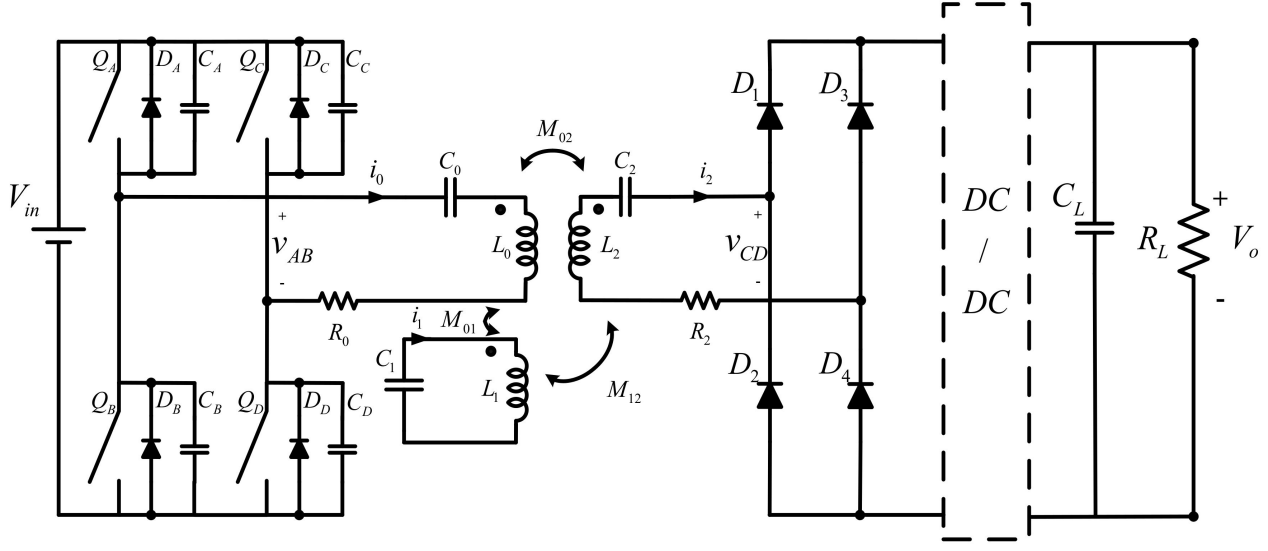

Figure 2. The main circuit of the three-winding IPT.

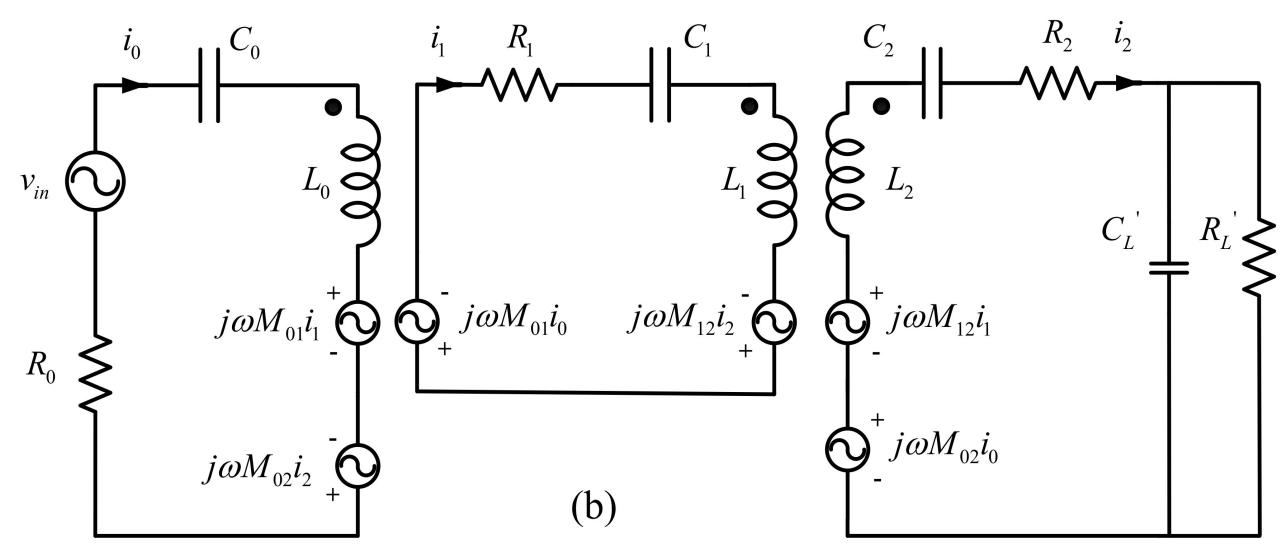

(a)

(c)

Figure 3. The AC equivalent circuit of the three-winding IPT (a) primary winding, (b) third winding, (c) secondary winding. 
At a resonant frequency, the reactance of leakage inductance is equal to the reactance of the compensating capacitor. As a result, the equations of the three-winding circuit are expressed as follows:

$$
\begin{gathered}
v_{i n}=R_{0} i_{0}+j \omega M_{01} i_{1}-j \omega M_{02} i_{2} \\
j \omega M_{01} i_{0}+R_{1} i_{1}-j \omega M_{12} i_{2}=0
\end{gathered}
$$

and

$$
-\left(j \omega M_{12} i_{1}+j \omega M_{02} i_{0}\right)+\left(R_{2}+R_{L}^{\prime}\right) i_{2}=0
$$

From (2) and (3), one can obtain the $i_{1}$ and $i_{2}$ as follows:

$$
i_{1}=\frac{-j \omega M_{01}\left(R_{2}+R_{L^{\prime}}\right)-\omega^{2} M_{02} M_{12}}{R_{1}\left(R_{2}+R_{L^{\prime}}\right)+\omega^{2} M_{12}^{2}} i_{0}
$$

and

$$
i_{2}=\frac{\omega^{2} M_{01} M_{12}+j \omega M_{02} R_{1}}{R_{1}\left(R_{2}+R_{L^{\prime}}\right)+\omega^{2} M_{12}^{2}} i_{0}
$$

In Equation (4), the product of multiplying $M_{02}$ and $M_{12}$ is very small because both parameters are less than $m H$. Moreover, in Equation (5), the product of multiplying $M_{01}$ and $M_{12}$ is also very small. As a result, Equations (4) and (5) can be simplified as follows:

$$
i_{1}=\frac{-j \omega M_{01}\left(R_{2}+R_{L^{\prime}}\right)}{R_{1}\left(R_{2}+R_{L^{\prime}}\right)+\omega^{2} M_{12}^{2}} i_{0}
$$

and

$$
i_{2}=\frac{j \omega M_{02} R_{1}}{R_{1}\left(R_{2}+R_{L}^{\prime}\right)+\omega^{2} M_{12}^{2}} i_{0}
$$

Inputting (6) and (7) into (1), one can obtain

$$
v_{\text {in }}=\left(R_{0}+\frac{\omega^{2} M_{01}^{2}\left(R_{2}+R_{L^{\prime}}\right)+\omega^{2} M_{02}^{2} R_{1}}{R_{1}\left(R_{2}+R_{L^{\prime}}\right)+\omega^{2} M_{12}^{2}}\right) i_{0}
$$

From (8) and by assuming the input reactive power is zero, one can obtain the input power as follows:

$$
P_{i}^{3 c}=v_{i n} i_{0}=\left(R_{0}+\frac{\omega^{2} M_{01}^{2}\left(R_{2}+R_{L^{\prime}}\right)+\omega^{2} M_{02}{ }^{2} R_{1}}{R_{1}\left(R_{2}+R_{L^{\prime}}\right)+\omega^{2} M_{12}^{2}}\right) i_{0}{ }^{2}
$$

The output power of the three-winding is

$$
P_{o}^{3 c}=i_{2}^{2} R_{L}^{\prime}
$$

Inputting (7) into (10), one can derive the output power as

$$
P_{o}^{3 c}=R_{L} \frac{\omega^{2} M_{02}^{2} R_{1}^{2}}{\left(R_{1}\left(R_{2}+R_{L^{\prime}}\right)+\omega^{2} M_{12}^{2}\right)^{2}} i_{0}^{2}
$$

From (9) and (11), the efficiency of the three-winding can be obtained as follows:

$$
\eta_{3 c}=\frac{P_{o}^{3 c}}{P_{i}^{3 c}}=\frac{R_{L^{\prime}} \frac{\omega^{2} M_{02}^{2} R_{1}^{2}}{\left(R_{1}\left(R_{2}+R_{L}^{\prime}\right)+\omega^{2} M_{12}^{2}\right)^{2}} i_{0}^{2}}{\left(R_{0}+\frac{\omega^{2} M_{01}^{2}\left(R_{2}+R_{L}^{\prime}\right)+\omega^{2} M_{02}{ }^{2} R_{1}}{R_{1}\left(R_{2}+R_{L}^{\prime}\right)+\omega^{2} M_{12}^{2}}\right) i_{0}^{2}}
$$

From (12), we can observe that the efficiency of the IPT is related to the parameters of $\omega, R_{s}, R_{1}, R_{2}, R_{L}{ }^{\prime}, M_{01}, M_{02}$, and $M_{12}$. However, when the parameter $M_{02}$ is increased, the efficiency always increases. 


\section{Design of Predictive Controller of a Three-Winding IPT System}

Predictive control has been in development for over four decades. It belongs to the class of model-based control, which requires precise parameters of the uncontrolled plant. This control has been applied in the manufacturing of paper, food, and furnaces, and in petrochemical and mining industries for forty years [11,12]. This type of control has many advantages. For example, it can be used for single-input and single-output processes and multi-input and multi-output processes. It is the only method that can handle constraints in a systematic way during the design of a controller. Recently, this predictive control has been widely used in power converters and electrical drives because of the powerful computational abilities of digital signal processors (DSPs) [13]. In this paper, a predictive voltage controller and a predictive current controller are used as a part of the considered inductive power transfer system. The details are as follows:

From Figure 2, the time-lag of the H-bridge is very short because the H-bridge is switched to a $77 \mathrm{kHz}$ high-frequency. As a result, a major delay-time comes from the inductance of the DC/DC buck converter, the filtering capacitance $C_{L}$, and the output resistance $R_{L}$. The transfer function of the whole IPT system, therefore, is expressed as follows:

$$
\frac{v_{o}(s)}{d(s)}=\frac{V_{i n}}{s^{2} L C_{L}+s L / R_{L}+1}
$$

where $v_{0}$ is the output voltage, $d$ is the duty cycle of the buck converter, $V_{i n}$ is the input DC voltage, $s$ is the differential operator, $L$ is the inductor of the buck converter, $C_{L}$ is the output capacitor of the buck converter, and $R_{L}$ is the output resistor load. The relationship between the duty cycle and the analog signal, which is used to compare the triangular carrier, is

$$
\frac{d(s)}{u(s)}=\frac{1}{V_{M}}
$$

where $V_{M}$ is the peak value of the PWM carrier, and $u(s)$ is the analog signal that is used to compare the triangular carrier. From (13) and (14), one can obtain

$$
\frac{v_{o}(s)}{u(s)}=\frac{1}{V_{M}} \frac{V_{\text {in }}}{s^{2} L C_{L}+s L / R_{L}+1}
$$

Taking the z-transform of Equation (15) and considering the zero-order hold, one can obtain

$$
\begin{aligned}
\frac{v_{o}(\mathbf{z})}{u(\mathbf{z})} & =Z\left(\frac{1}{V_{M}} \frac{V_{i n}}{s^{2} L C_{L}+s L / R_{L}+1} \cdot \frac{1-e^{-T s}}{s}\right) \\
& =\frac{b_{0}+b_{1} z^{-1}}{1-a_{1} z^{-1}+a_{2} z^{-2}}
\end{aligned}
$$

and

$$
\begin{gathered}
a_{1}=\frac{2 L C_{L}+\frac{L}{R_{L}} T}{L C_{L}+\frac{L}{R_{L}} T+T^{2}} \\
a_{2}=\frac{L C_{L}}{L C_{L}+\frac{L}{R_{L}} T+T^{2}} \\
b_{0}=T^{3} \frac{V_{\text {in }}}{V_{M}\left(L C_{L}+T \frac{L}{R_{L}}+T^{2}\right)} \\
b_{1}=0
\end{gathered}
$$

where $T$ is the sampling time of the voltage-loop of the IPT, which is $14 \mu$ s. From (16), one can obtain the output voltage of the IPT $v_{0}(k)$, which is related to the parameters $a_{1}, a_{2}, b_{0}$, and the control input $u(k)$ as follows:

$$
v_{o}(k)=a_{1} v_{o}(k-1)-a_{2} v_{o}(k-2)+b_{0} u(k)
$$


By choosing the vector $x_{m}(k)^{T}=\left[v_{0}(k) v_{0}(k-1)\right]$ and using a state-space representation, one can rewrite the state equation of (21) as follows

$$
x_{m}(k+1)=A_{m} x_{m}(k)+B_{m} u(k+1)
$$

and

$$
\begin{gathered}
A_{m}=\left[\begin{array}{cc}
a_{1} & -a_{2} \\
1 & 0
\end{array}\right] \\
B_{m}=\left[\begin{array}{c}
b_{0} \\
0
\end{array}\right] \\
x_{m}(k)=\left[\begin{array}{c}
v_{0}(k) \\
v_{0}(k-1)
\end{array}\right]
\end{gathered}
$$

The output equation of (21) can be expressed as

$$
y(k)=C_{m} x_{m}(k)
$$

and

$$
C_{m}=\left[\begin{array}{ll}
1 & 0
\end{array}\right]
$$

From (22), one can derive

$$
\begin{aligned}
\Delta x_{m}(k+1) & =x_{m}(k+1)-x_{m}(k) \\
& =A_{m} \Delta x_{m}(k)+B_{m} \Delta u(k)
\end{aligned}
$$

From (26), by using a similar method, one can obtain

$$
y(k+1)-y(k)=C_{m} A_{m} \Delta x_{m}(k)+C_{m} B_{m} \Delta u(k)
$$

Then, we can define the augmented variable as follows:

$$
X_{A}(k)=\left[\begin{array}{c}
\Delta x_{m}(k) \\
y(k)
\end{array}\right]=\left[\begin{array}{c}
\Delta v_{0}(k) \\
\Delta v_{0}(k-1) \\
v_{0}(k)
\end{array}\right]
$$

Then from (30), we can obtain

$$
X_{A}(k+1)=A_{A} X_{A}(k)+B_{A} \Delta u(k)
$$

and

$$
\begin{gathered}
A_{A}=\left[\begin{array}{cc}
A_{m} & 0 \\
C_{m} A_{m} & 1
\end{array}\right] \\
B_{A}=\left[\begin{array}{c}
B_{m} \\
C_{m} B_{m}
\end{array}\right]
\end{gathered}
$$

The output is expressed as follows:

$$
y(k)=C_{A} X_{A}(k)
$$

and

$$
C_{A}=\left[\begin{array}{ll}
0_{m} & 1
\end{array}\right]
$$

From (31), we can derive the predictive state variable vector as follows:

$$
\hat{X}_{A}(k+1)=A_{A} \hat{X}_{A}(k)+B_{A} \Delta u(k)
$$


The predictive output can be expressed as

$$
\hat{y}(k+1)=C_{A} \hat{X}_{A}(k+1)
$$

Submitting (36) into (37), we can derive

$$
\hat{y}(k+1)=F \hat{X}(k)+\Phi \Delta u(k)
$$

and

$$
\begin{aligned}
& F=C_{A} A_{A} \\
& \Phi=C_{A} B_{A}
\end{aligned}
$$

We can define the performance index $J_{q v}$ as follows:

$$
J_{q v}=\left(y^{R e f}-\hat{y}(k+1)\right)^{T}\left(y^{R e f}-\hat{y}(k+1)\right)+\Delta u(k)^{T} \gamma_{\omega} \Delta u(k)
$$

where $y^{\text {Ref }}$ is the reference command. By choosing $y^{\text {Ref }}=v^{\text {Ref }}$ and submitting (38)-(40) into (41), one can obtain

$$
\begin{aligned}
\Delta u(k) & =\left(\Phi^{T} \Phi+\gamma_{\omega}\right)-{ }^{1} \Phi^{T}\left(y^{R e f}-F X(k)\right) \\
& =\frac{1}{b_{0}^{2}+\gamma_{\omega}} b_{0}\left[\left(v^{R e f}-v_{0}(k)\right)-\left(a_{1}+b_{1}\right) \Delta v_{0}(k)+\left(a_{2}+b_{1}\right) \Delta v_{0}(k-1)\right]
\end{aligned}
$$

where $\gamma_{\omega}$ is the weighting factor and $X(k)$ is the state variable vector, which includes two state variables, $v_{o}(k)$ and $v_{o}(k-1)$. In the real world, the control input $u(k)$ is the summation of $\Delta u(k)$ and can be expressed as follows:

$$
u(k)=u(k-1)+\Delta u(k)
$$

The proposed voltage predictive controller, which is shown in Equation (42), is shown in Figure 4a. By using Equation (42), the proposed current predictive controller can be obtained and is shown in Figure $4 \mathrm{~b}$, which is very similar to the predictive voltage controller design in our study and can be used as a constant current controller of a battery set. Figure $4 \mathrm{c}, \mathrm{d}$ show the block diagrams of the implemented PI controllers, which are used for comparison. It may be unfair to compare a predictive control system with a simple PI controller tuned using the pole placement method. In the future, more advanced control methods, such as optimal control, adaptive control, or robust control could be used and compared with the predictive control proposed in this paper.

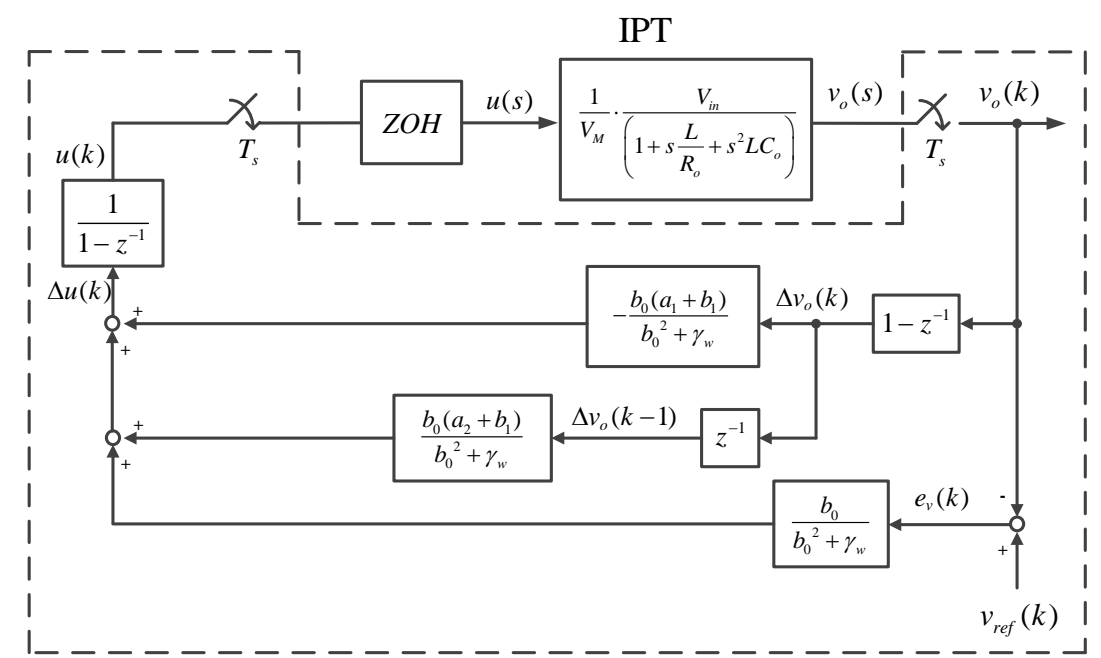

(a)

Figure 4. Cont. 


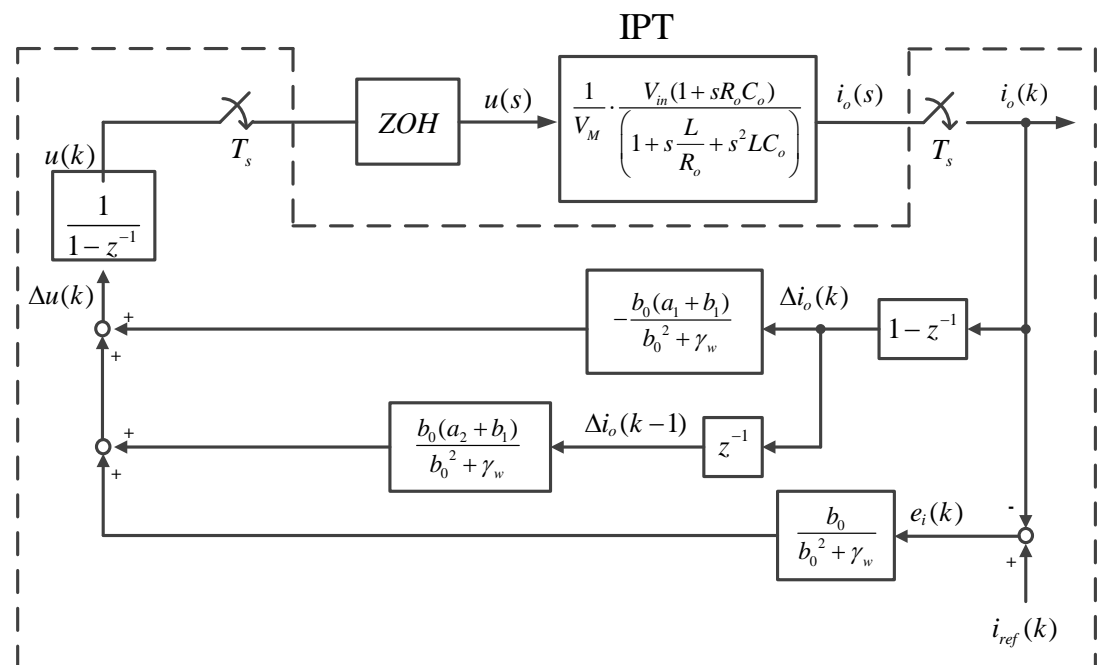

(b)

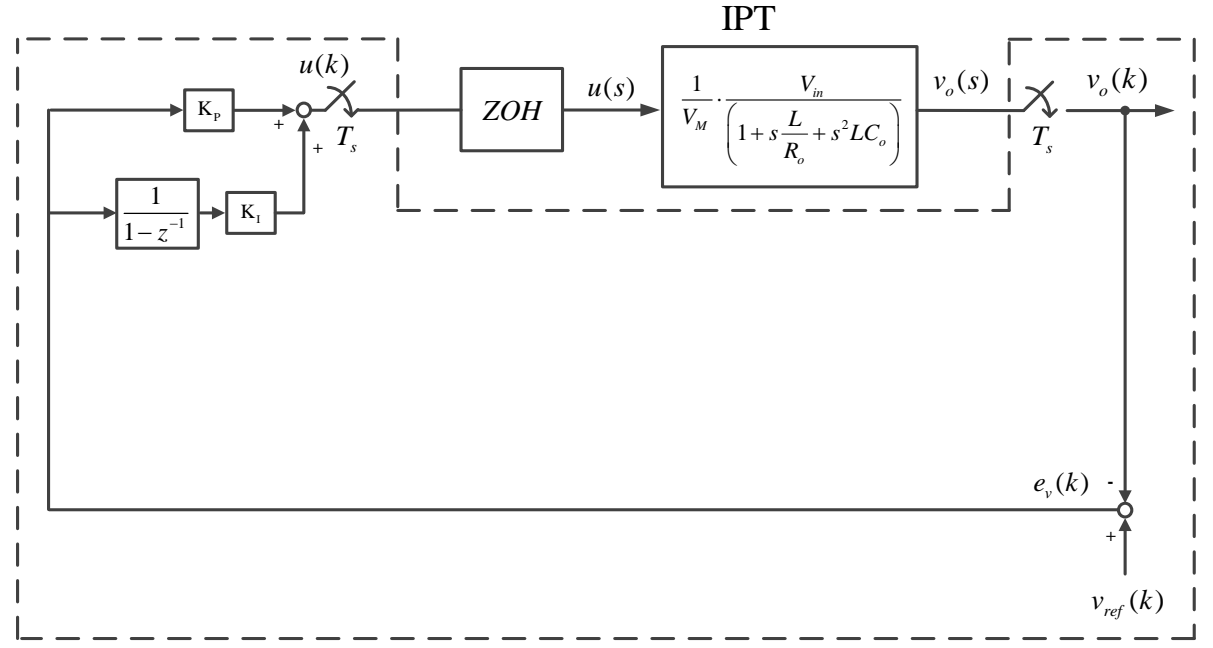

(c)

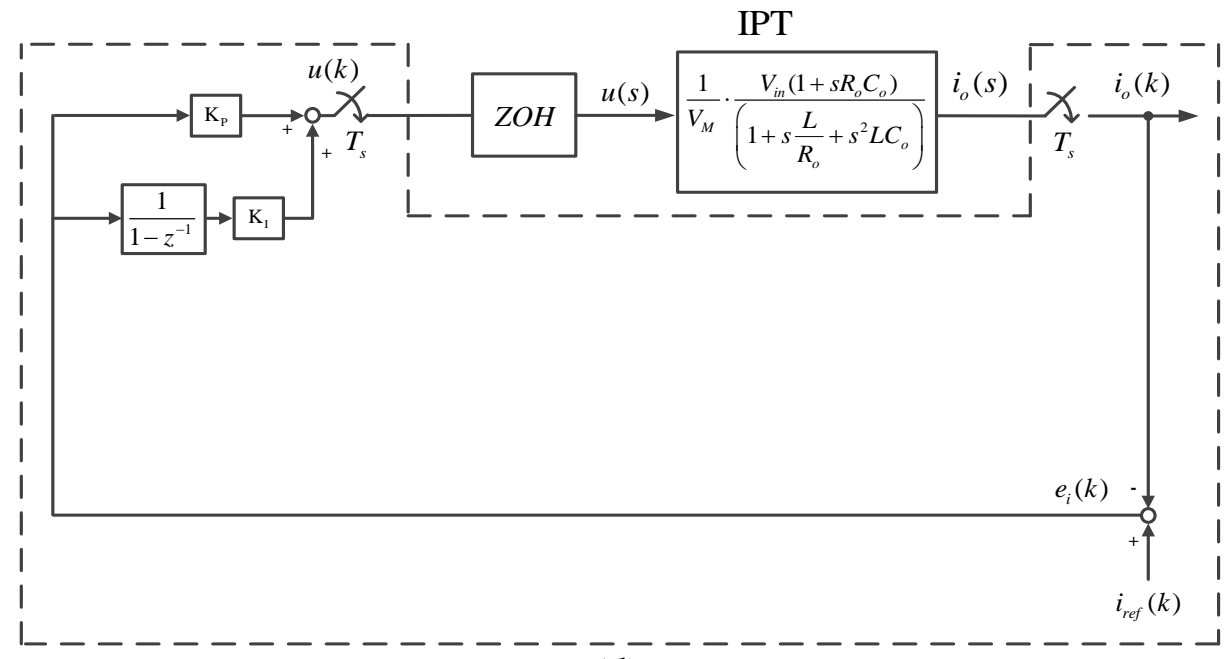

(d)

Figure 4. The proposed different controllers for an IPT (a) predictive voltage control and (b) predictive current control. (c) proportional-intrgral voltage control (d) proportional-integral current control.

\section{Implementation}

The implemented IPT system has three major parts: three windings, hardware circuits, and a DSP. The photograph of the hardware circuits, shown in Figure $5 \mathrm{a}$, consists of an 
H-bridge, a primary compensation capacitor, a secondary compensation capacitor, a third compensation capacitor, a full-bridge rectifier, a DC/DC buck converter, an overcurrent protection circuit, a voltage sensing circuit, a current sensing circuit, gate drivers, and power supplies. A DSP, type TMS 320F2808, is used as the control center of the IPT system. The control algorithm is implemented by $C$ language. The configuration of the three windings, shown in Figure 5b, includes a primary winding, a secondary winding, and a third winding. The specifications of the implemented IPT system are shown in Table 1. The details of the primary winding, secondary winding, and third winding are shown in Table 2.

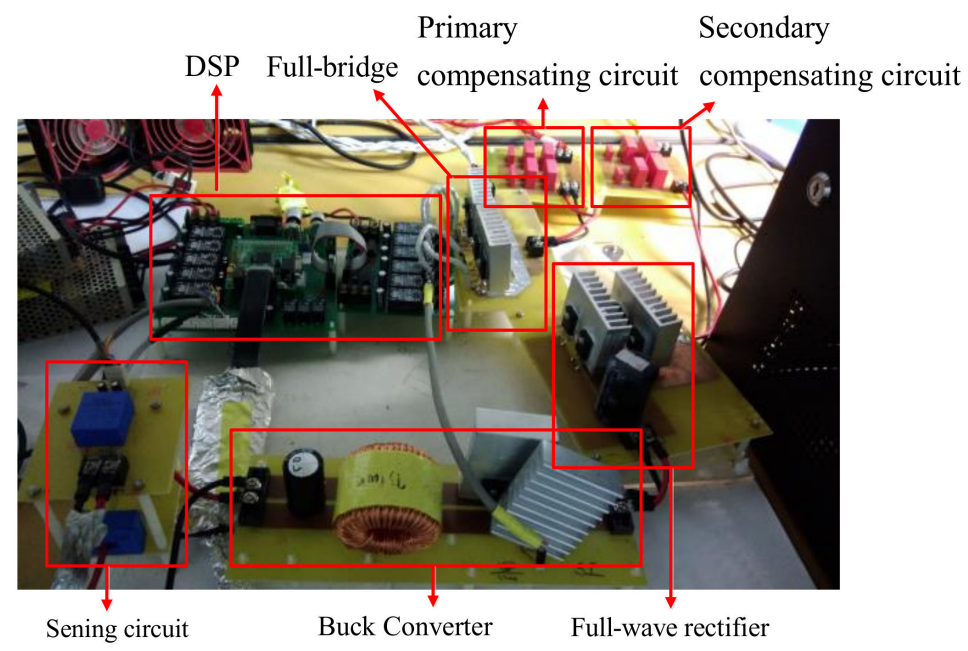

(a)

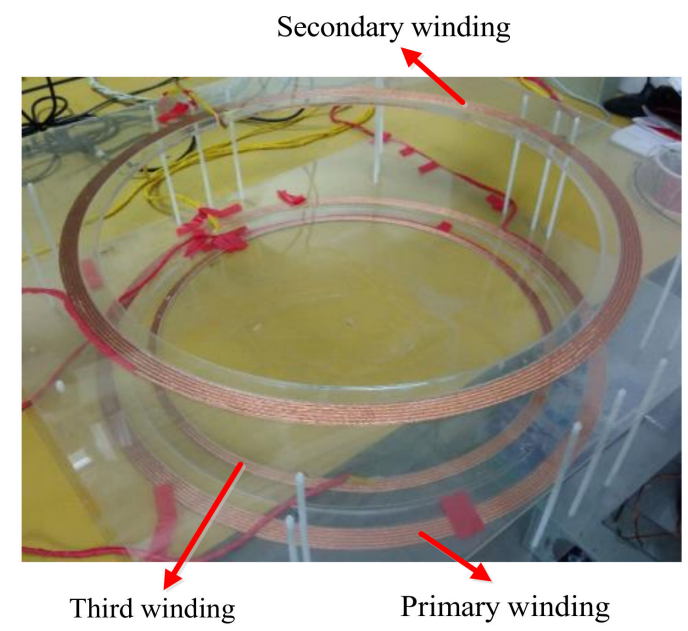

(b)

Figure 5. The photographs of the implemented IPT system: (a) hardware circuits (b) threewinding configuration.

Table 1. Specifications of the three-winding IPT system.

\begin{tabular}{cc}
\hline Specifications & Values \\
\hline Input voltage & $220 \mathrm{~V}$ \\
Output current & $10 \mathrm{~A}$ \\
Output power & $2 \mathrm{~kW}$ \\
Switching frequency & $77 \mathrm{kHz}$ \\
Standard air gap & $20 \mathrm{~cm}$ \\
\hline
\end{tabular}


Table 2. Geometrical parameters.

\begin{tabular}{ccc}
\hline Primary & Secondary & Third \\
\hline 5 turns & 6 turns & 4 turns \\
$62 \mathrm{~cm}$ & $60 \mathrm{~cm}$ & $52 \mathrm{~cm}$ \\
\hline
\end{tabular}

\section{Simulations and Experimental Results}

In this paper, Matlab software, which is a powerful computing tool, was used to carry out the simulation. The block diagram of the simulation is shown in Figure 6. First, the reference voltage command is compared to the output voltage of the IPT system to obtain the error $e_{v}(k)$. Next, the error $e_{v}(k)$ is multiplied by $\frac{b_{0}}{b_{0}^{2}+\gamma_{w}}$ to obtain $e_{1}(k)$. The $\Delta v_{0}(k)$, which is the difference between the output voltage $v(k)$ and $v(k-1)$, is multiplied by $-\frac{b_{0}\left(a_{1}+b_{1}\right)}{b_{0}^{2}+\gamma_{w}}$ to obtain $e_{2}(k)$. The delay of $\Delta v_{0}(k)$, which is $\Delta v_{0}(k-1)$, is multiplied by $\frac{b_{0}\left(a_{2}+b_{1}\right)}{b_{0}^{2}+\gamma_{w}}$ to obtain $e_{3}(k)$. After that, the $\Delta u(k)$, which is the summation of the $e_{1}(k), e_{2}(k)$, and $e_{3}(k)$ can be computed. Finally, the control input $u(k)$, which is the integration of the $\Delta u(k)$, is sent to the plant, which is the IPT, to produce the output voltage $v_{0}(s)$. A closed-loop IPT system is thus obtained.

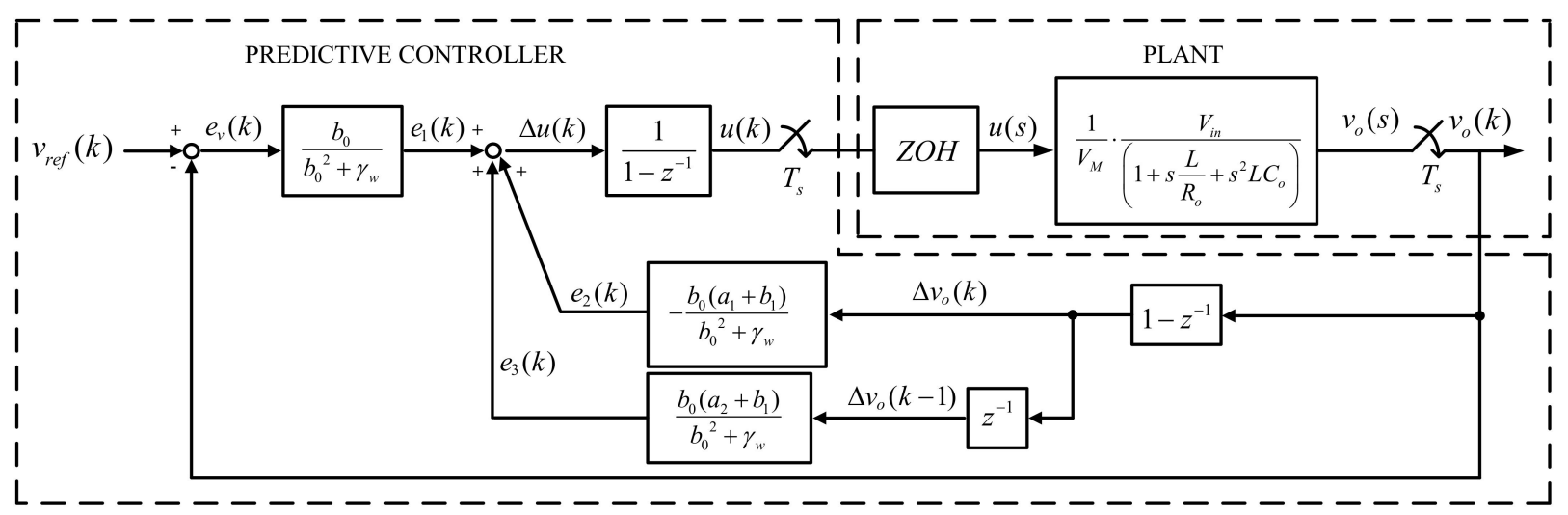

Figure 6. The block diagram of the simulation program using Matlab.

Several experimental results are shown here to validate the theoretical analysis and simulated results. The switching frequency of the $\mathrm{H}$-bridge is $77 \mathrm{kHz}$, the sampling interval of the current-loop is $14 \mu \mathrm{s}$, and the sampling interval of the voltage loop is also $14 \mu \mathrm{s}$. The simulated waveforms use the resistance, self-inductance, and mutual inductance of the coils by using the off-line measurement of the real IPT system. The predictive step is one step ahead, and the control horizon is one. The uncontrolled plant has the following transfer functions. For voltage control, the transfer function is

$$
\frac{v_{o}(s)}{u(s)}=\frac{44}{1+0.0000953 s+0.000000573 s^{2}}
$$

and for current control, the transfer function is

$$
\frac{i_{o}(s)}{u(s)}=\frac{44(1+0.0000953 s)}{1+0.0000953 s+0.000000573 s^{2}}
$$

The predictive controller uses two weighting factors $-\gamma_{\omega}=0.1$ and $\gamma_{\omega}=0.3-$ for the voltage control system to compare their voltage responses. The smaller weighting factor produces a quicker voltage response, which means that the control input energy is less important and the output voltage response is more important. The predictive controller uses the weighting factors: $\gamma_{\omega}=0.01$ and $\gamma_{\omega}=0.03$ for the current control system to compare their current responses. The smaller weighting factor produces a quicker current 
response, which means that the control input energy is less important and the output current response is more important. The PI controller of the voltage-loop includes $K_{p}=0.3$ and $K_{i}=7$. The PI controller of the current-loop includes $K_{p}=0.06$ and $K_{i}=180$. The parameters of $K_{p}$ and $K_{i}$ are obtained by using a pole assignment method.

Several simulated and measured results are demonstrated in this paper. Figure $7 \mathrm{a}, \mathrm{b}$ show the H-bridge output voltage $v_{A B}$ and output current $i_{0}$ at $200 \mathrm{~W}$. Figure 7a demonstrates the simulated waveforms, and Figure $7 \mathrm{~b}$ demonstrates the measured waveforms. The $v_{A B}$ is a symmetrical square-wave voltage, but the $i_{O}$ is a symmetrical triangular current due to the light load. The simulated and measured waveforms are quite similar; however, the measured output voltage $v_{A B}$ has obvious ringings due to the resonance of the stray capacitance and stray inductance. The ringings can be reduced if the layout of the main circuit is improved. Figure $8 \mathrm{a}, \mathrm{b}$ show the $\mathrm{H}$-bridge output voltage $v_{A B}$ and output current $i_{O}$ at $2 \mathrm{~kW}$. The $v_{A B}$ is a symmetrical square-wave voltage, but the $i_{0}$ is a near sinusoidal current due to the heavy load. Figure 8 a demonstrates the simulated waveforms, and Figure $8 \mathrm{~b}$ demonstrates the measured waveforms. They are also similar; however, the measured output voltage $v_{A B}$ has obvious ringings again. Figure $9 \mathrm{a}, \mathrm{b}$ show the measured waveforms under zero voltage switching conditions at $200 \mathrm{~W}$ and $2 \mathrm{~kW}$. Both figures show that the $v_{d s}$ reaches a zero voltage when the $v_{g s}$ gating signal is turned on, which implies that a zero voltage switching can be obtained. The measured voltage $v_{d s}$ has obvious ringings when the power switch is turned on. Figure $10 \mathrm{a}, \mathrm{b}$ show the measured secondary voltage $v_{C D}$ and secondary current $i_{2}$ at $200 \mathrm{~W}$ and $2 \mathrm{~kW}$. The secondary current $i_{2}$ is closer to a sinusoidal waveform as the output power is increased to $2 \mathrm{~kW}$. Figure 11a,b show the measured voltages across the primary compensating capacitor $C_{0}$ and the secondary compensating capacitor $C_{2}$ at $200 \mathrm{~W}$ and $2 \mathrm{~kW}$. Both of the $v_{\mathrm{CO}}$ and $v_{\mathrm{C} 2}$ are near sinusoidal waveforms. In addition, the amplitude of $v_{\mathrm{C} 2}$ reaches $800 \mathrm{~V}$, and the amplitude of $v_{C O}$ reaches $1300 \mathrm{~V}$ at $2 \mathrm{~kW}$. It can be observed that high-stress capacitors should be used for $C_{1}$ and $C_{2}$ in this proposed IPT system. Figure 12a shows the measured third winding current $i_{1}$ and its compensation capacitor voltage $v_{C 1}$ at $200 \mathrm{~W}$, in which the phase difference between $i_{1}$ and $v_{C 1}$ is near $25^{\circ}$ at a light load. Figure $12 \mathrm{~b}$ shows the measured third winding current $i_{1}$ and its compensation capacitor voltage $v_{\mathrm{C} 1}$ at $2 \mathrm{~kW}$, in which the phase difference between $i_{1}$ and $v_{C 1}$ is near $90^{\circ}$ due to the heavy output load. The reason is that the third winding only has inductance and capacitance without any resistance. Figure 13a,b show the measured output voltage at $200 \mathrm{~W}$ and $2 \mathrm{~kW}$. The output inductor current $i_{L}$ is increased from $1.5 \mathrm{~A}$ to $13 \mathrm{~A}$ as the output power is increased from $200 \mathrm{~W}$ to $2 \mathrm{~kW}$. In addition, the inductance current has obvious ringings at $2 \mathrm{~kW}$. The main reason is that a heavy load creates more store energy in the inductance, which creates more ringings when the power switch is turned on or off. The output voltage, however, is very smooth since a large capacitance is used in this paper. Due to the high-frequency operation of the IPT, the reactances of the leakage inductances can be canceled by the reactances of the capacitors. As a result, the input power in the primary winding can be effectively transferred to the output power in the secondary winding.

From Figure 14a,b, Figure 15a,b and Figure 16a,b, we can see the dynamic performance of the proposed IPT. Figure 14a shows the measured output voltage responses during transient responses. The predictive controllers provide a lower overshoot than PI controllers. In addition, a smaller weight factor can provide lower overshoot response because the control input of the IPT system can increase the current, which creates more energy. Taking Figure $14 \mathrm{a}$ as an example, from $0 \mu s$ to $1 \mu s$, the performance index $J_{q v}$ shown in Equation (41) is 1.5 for the weighting factor $\gamma_{\omega}=0.1$, and the performance index $J_{q v}$ becomes 2.3 for the weighting factor $\gamma_{\omega}=0.3$. The performance index can be calculated by using voltage error, control input $\Delta u(k)$, weighting factor $\gamma_{\omega}$, and a time interval. Figure $14 \mathrm{~b}$ shows the measured output voltage responses during load disturbance. An external load of $4 \mathrm{~A}$ is added at $20 \mathrm{~ms}$. A smaller weight factor provides a quicker recovery response again. Figure 15a shows the measured output current transient responses, and Figure $15 \mathrm{~b}$ shows the load disturbance responses of the output currents. The predictive 
controllers provide faster recovery times than the PI controllers. In addition, a smaller weight factor can provide a quicker response because the control input of the IPT system can increase the current, which creates more energy. Figure 16 shows the measured battery voltage and its charging current by using the proposed IPT system. The battery is charged using a constant current at the beginning and then is charged using a constant voltage. The largest charging current is set as $15 \mathrm{~A}$ due to the limitation of the battery. However, when the required current charging time is reached, the charging is gradually reduced to $1 \mathrm{~A}$. Figure 17a demonstrates the measured efficiency of the three-winding IPT at different distances between the primary winding and secondary winding. From Figure 17a, the shortest distance provides the highest efficiency for the IPT system. In addition, with a $20 \mathrm{~cm}$ air gap, the IPT system reaches $88 \%$ efficiency at a $2 \mathrm{~kW}$ output. However, when the air gap increases, the efficiency of the IPT decreases. Figure $17 \mathrm{~b}$ demonstrates the measured efficiency of the three-winding IPT with different misalignments. From Figure 17b, the shortest misalignment, which is $0 \mathrm{~cm}$, provides the highest efficiency for the IPT. The operations of the IPT system in misaligned conditions are considered with the same model, but this misalignment could lead to changes in the mutual inductance between the windings and the assumptions made in Section 1 . This issue is very complex; as a result, the paper cannot provide a detailed analysis. Only experimental results are demonstrated in this paper.

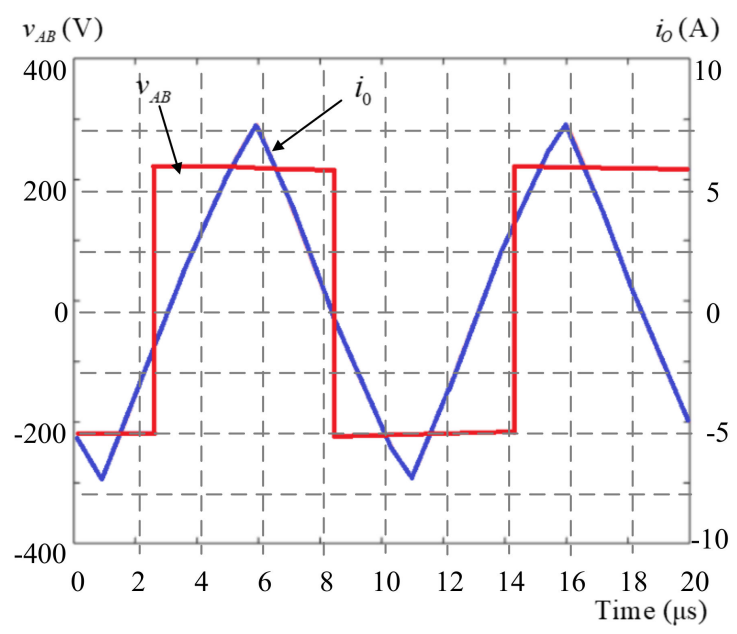

(a)

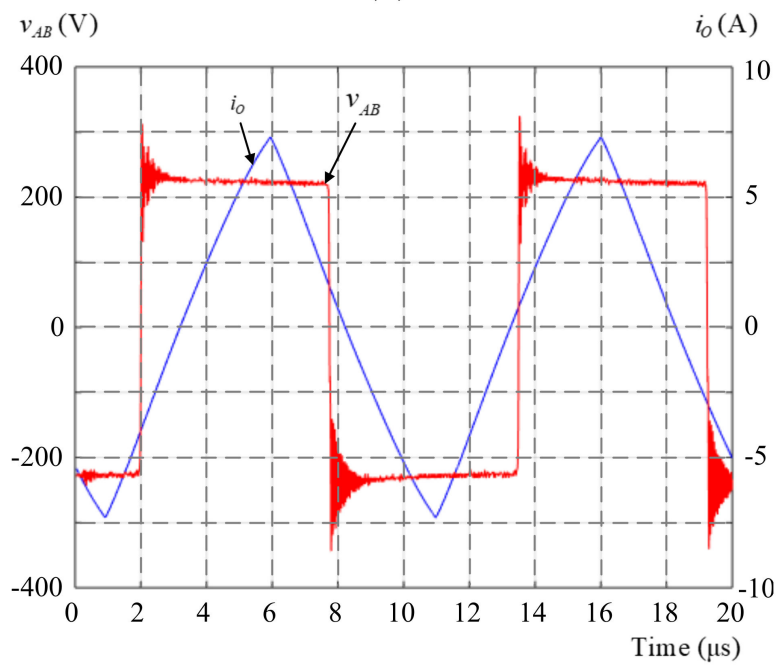

(b)

Figure 7. The full-bridge output voltage $v_{A B}$ and output current $i_{0}$ at $200 \mathrm{~W}$ : (a) simulated, (b) measured. 


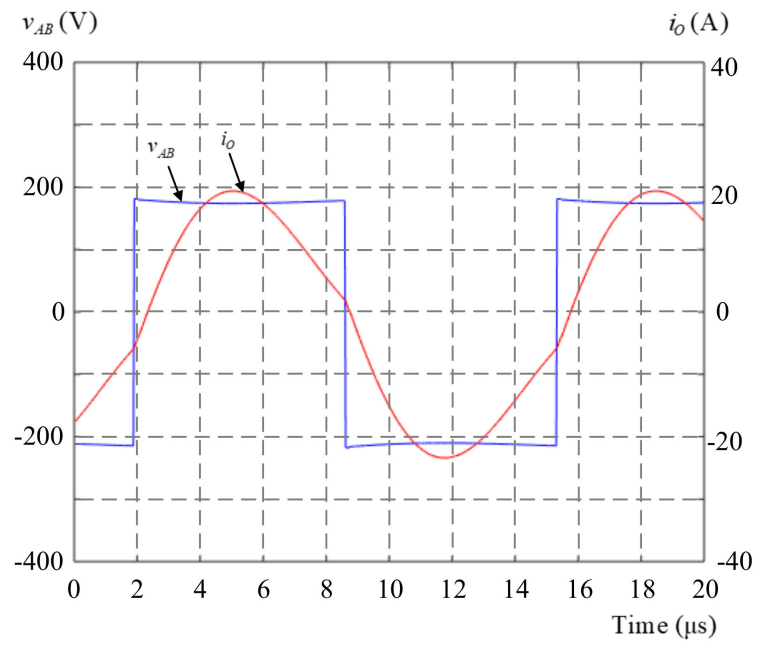

(a)

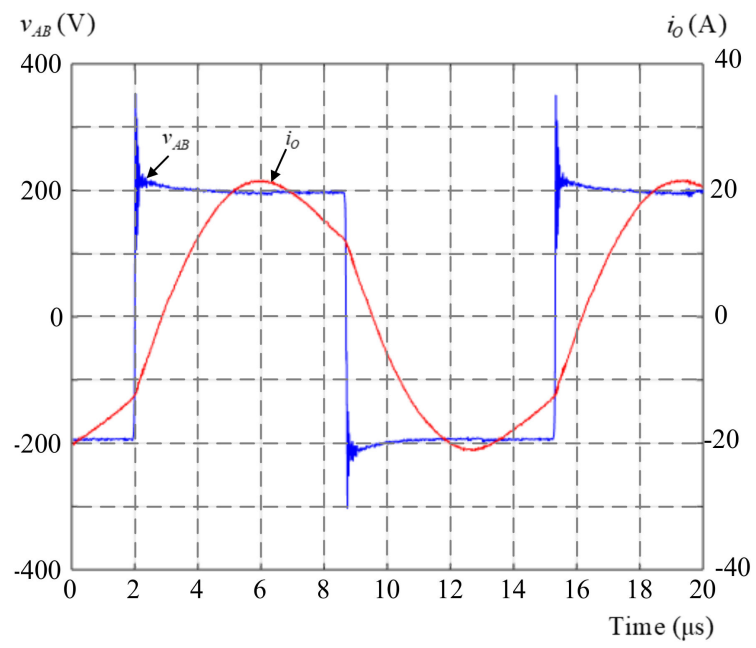

(b)

Figure 8. The full-bridge output voltage $v_{A B}$ and output current $i_{o}$ at $2 \mathrm{~kW}$ : (a) simulated, (b) measured.

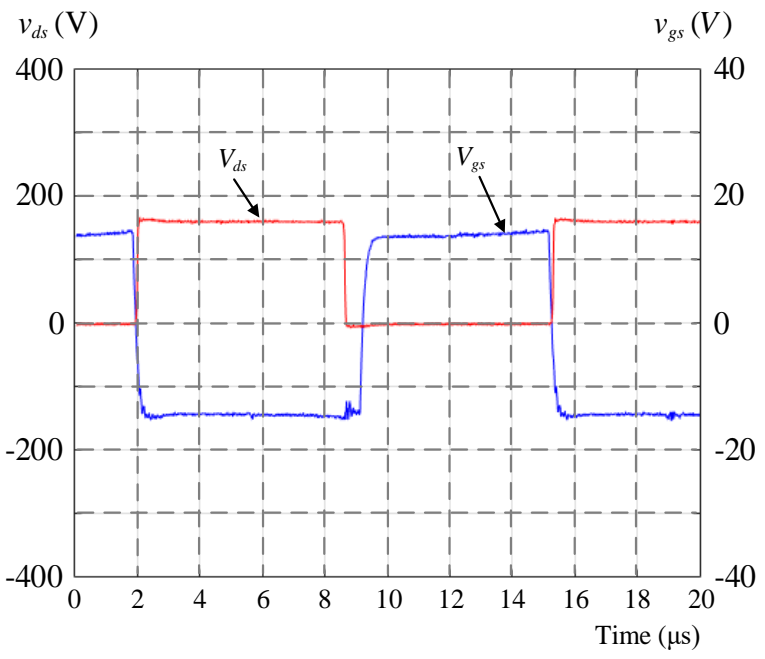

(a)

Figure 9. Cont. 


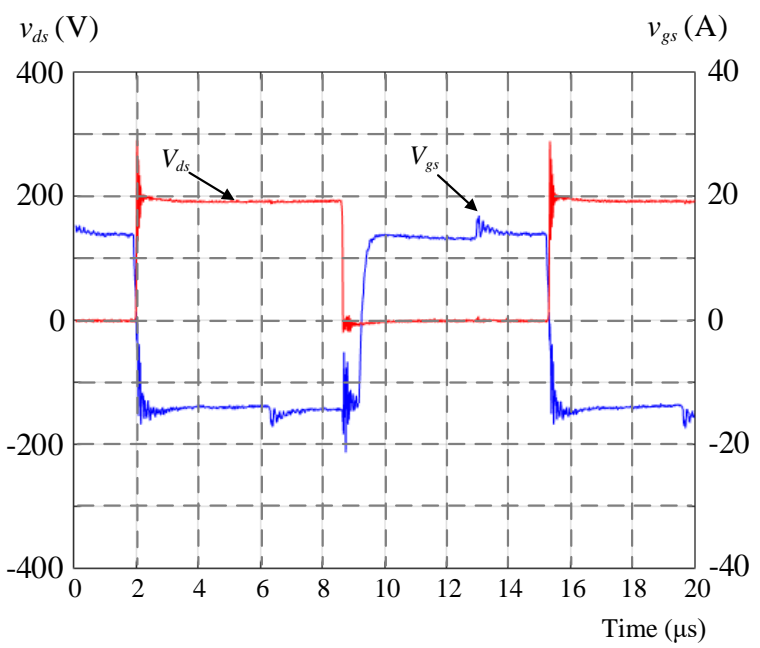

(b)

Figure 9. The measured waveforms $v_{d s}$ and $v_{g s}$ under zero voltage switching conditions at different output powers (a) $200 \mathrm{~W}$, (b) $2 \mathrm{~kW}$.

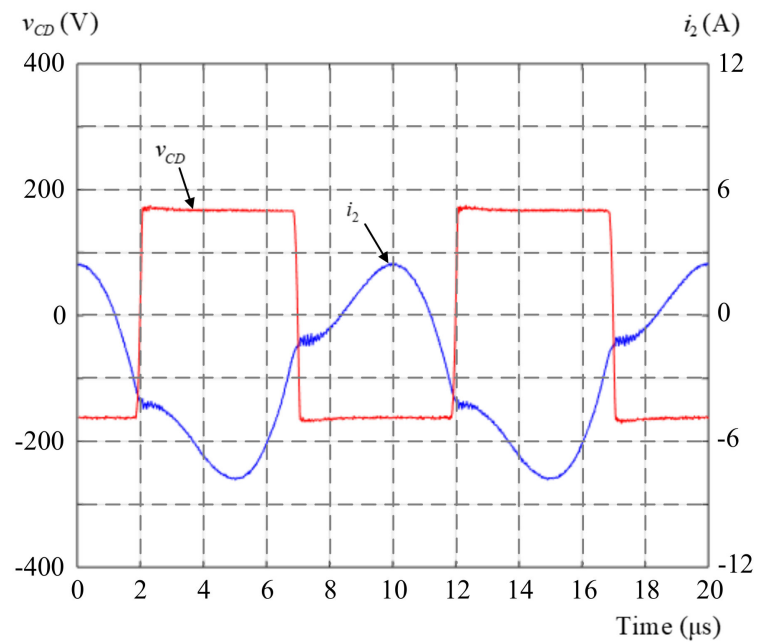

(a)

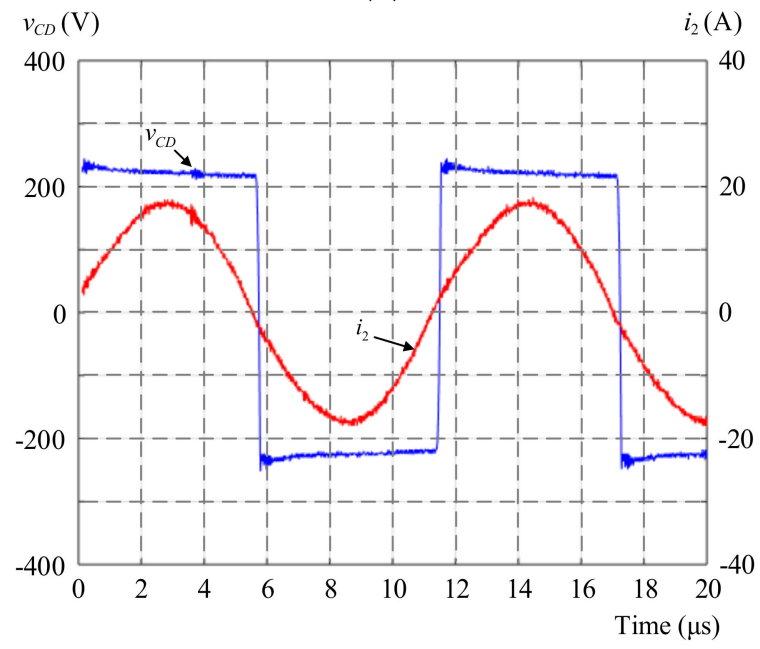

(b)

Figure 10. The measured secondary winding voltage $v_{C D}$ and secondary current $i_{2}$ at different output powers (a) $200 \mathrm{~W}$, (b) $2 \mathrm{~kW}$. 


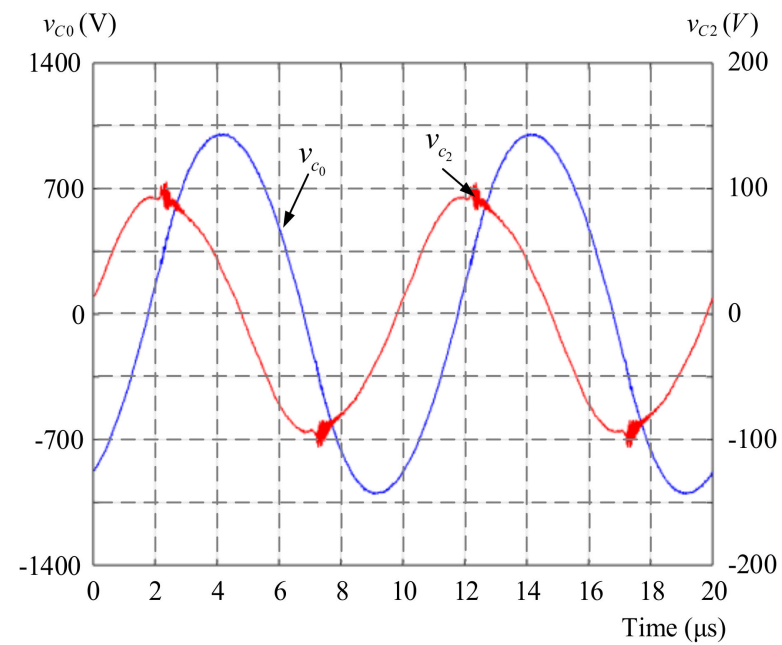

(a)

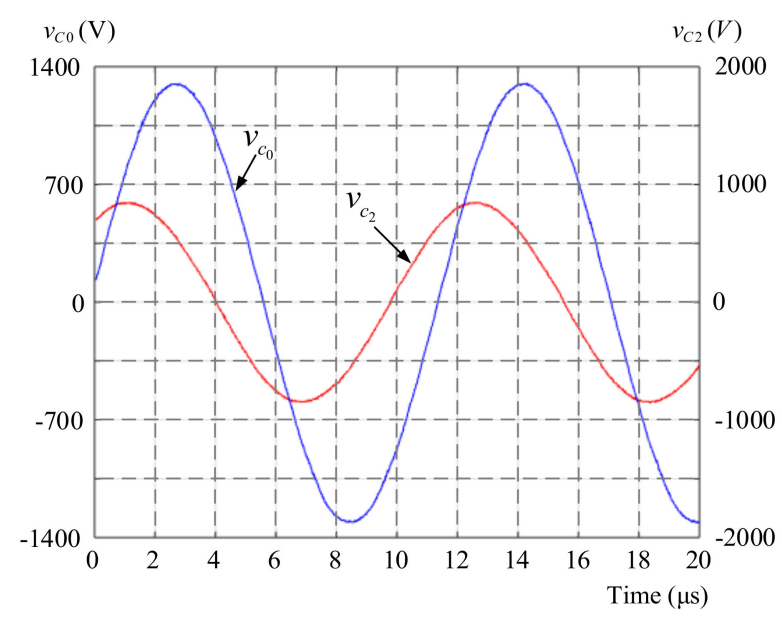

(b)

Figure 11. The measured voltages across the primary capacitor and secondary capacitor at different output powers (a) $200 \mathrm{~W}$, (b) $2 \mathrm{~kW}$.

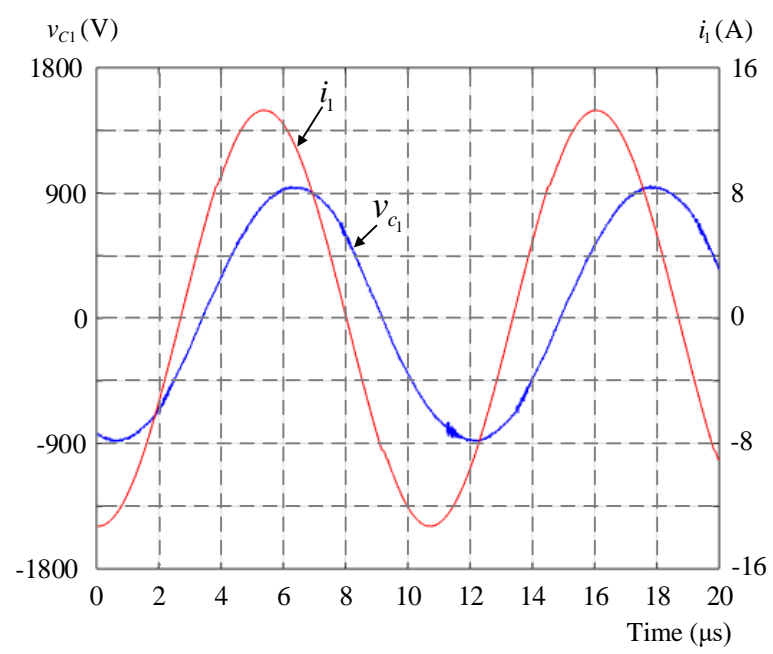

(a)

Figure 12. Cont. 


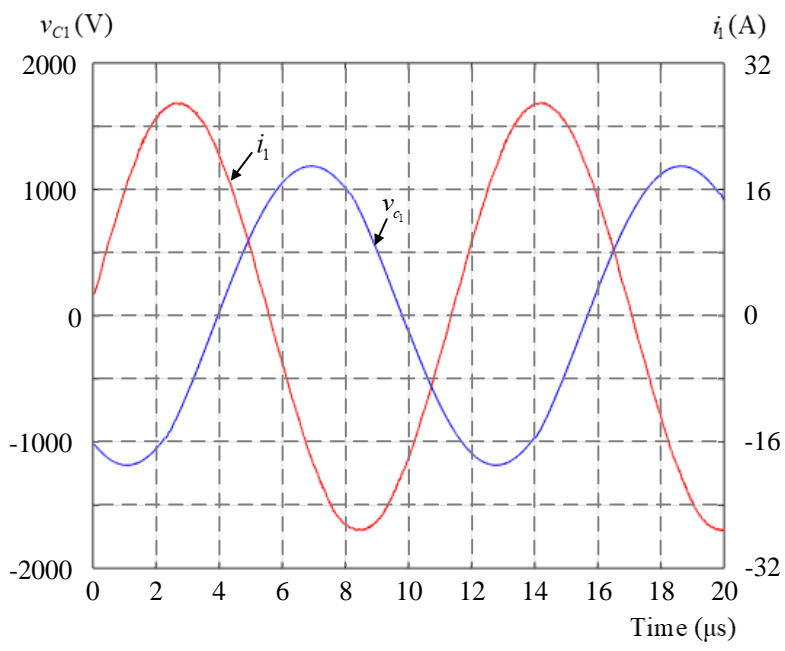

(b)

Figure 12. The measured third winding current $i_{1}$ and compensation capacitor voltage $v_{c 1}$ at different output powers (a) $200 \mathrm{~W}$, (b) $2 \mathrm{~kW}$.

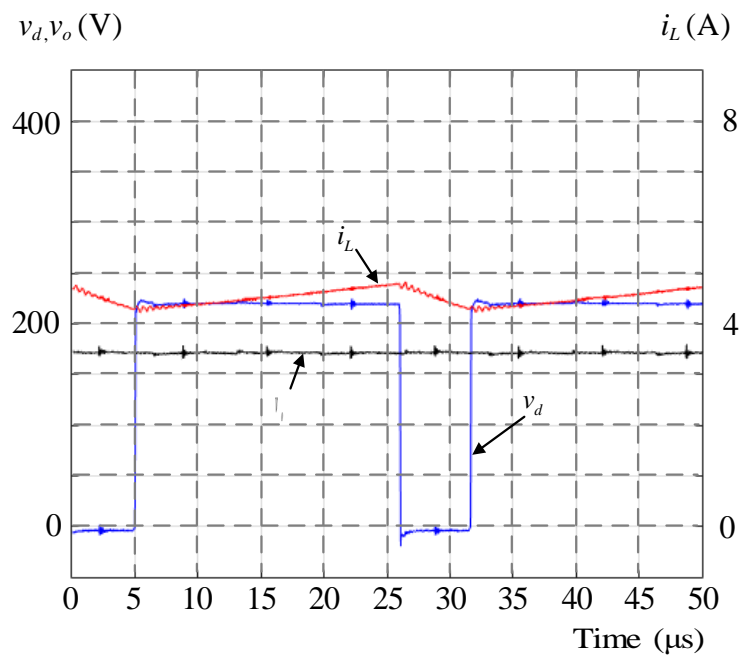

(a)

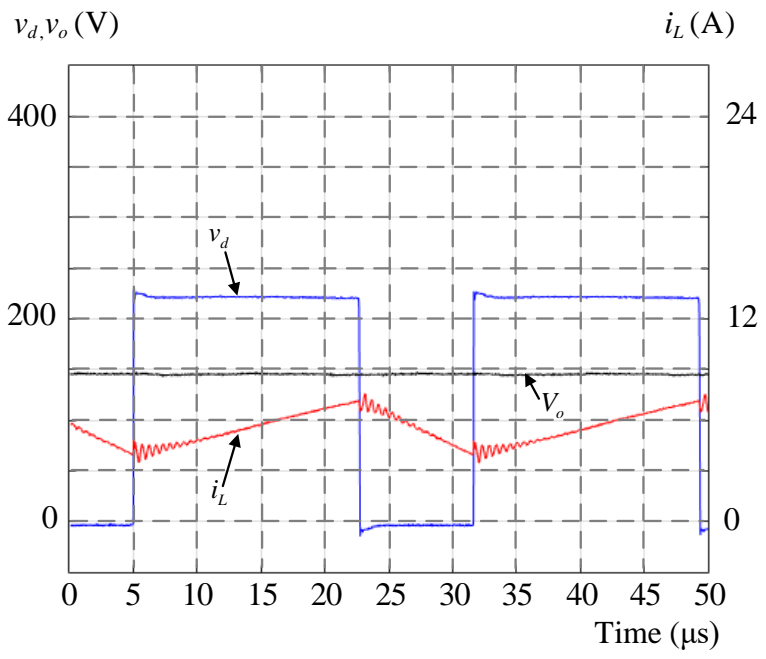

(b)

Figure 13. The output voltage $V_{o}$ and output inductor current $i_{L}$ measured by using a buck converter at different output powers (a) $200 \mathrm{~W}$, (b) $2 \mathrm{~kW}$. 


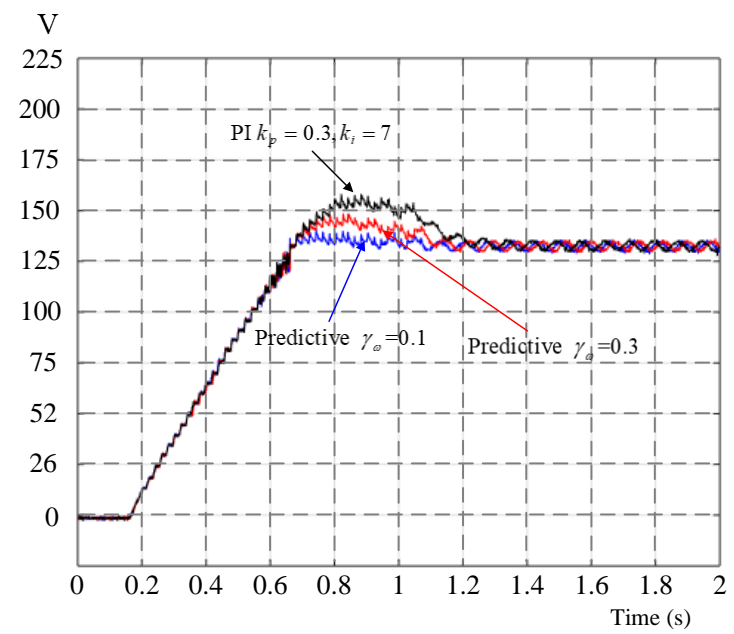

(a)

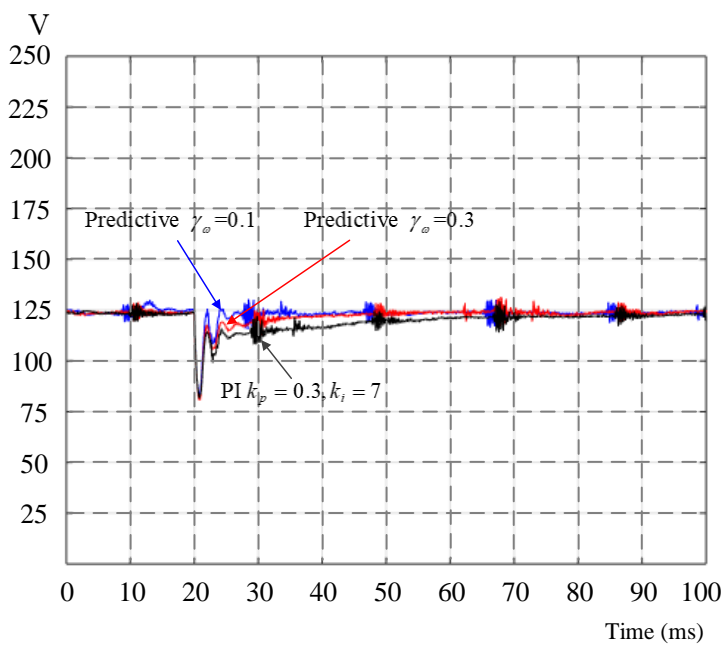

(b)

Figure 14. The measured output voltage responses: (a) transient, (b) load disturbance.

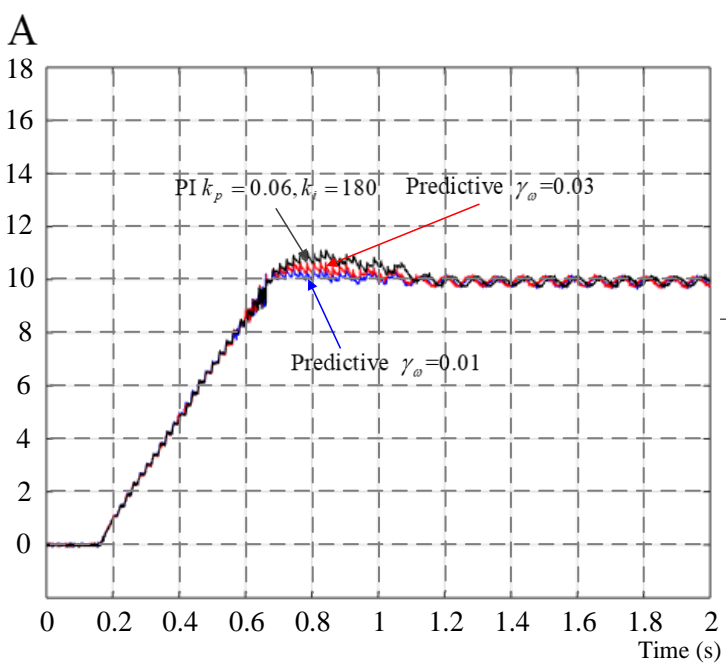

(a)

Figure 15. Cont. 


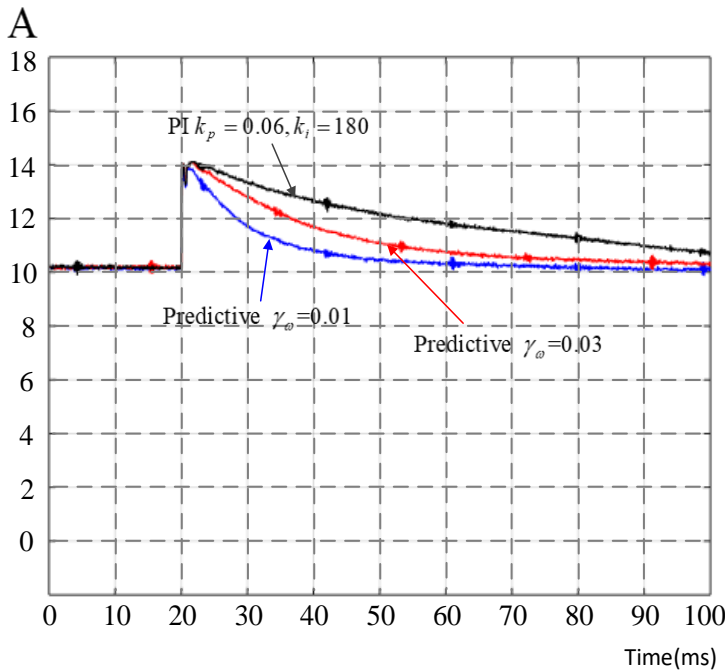

(b)

Figure 15. The measured output current responses: (a) transient, (b) load disturbance.

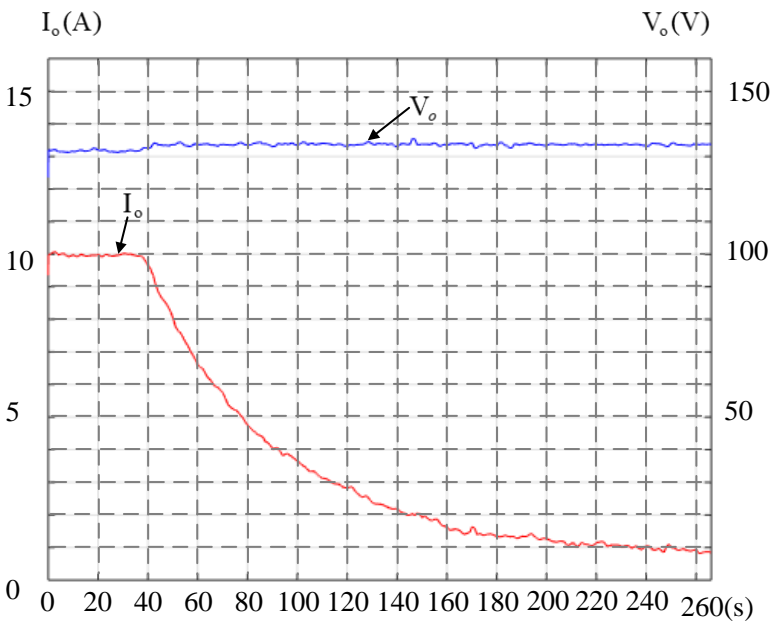

Figure 16. The measured battery voltage and its charging current.

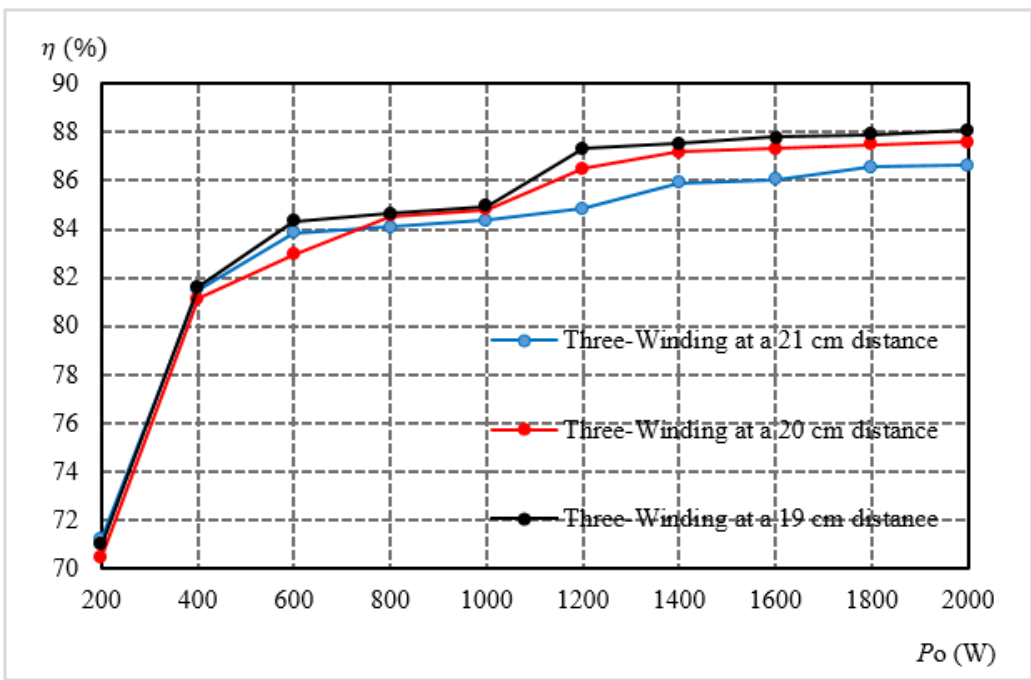

(a)

Figure 17. Cont. 


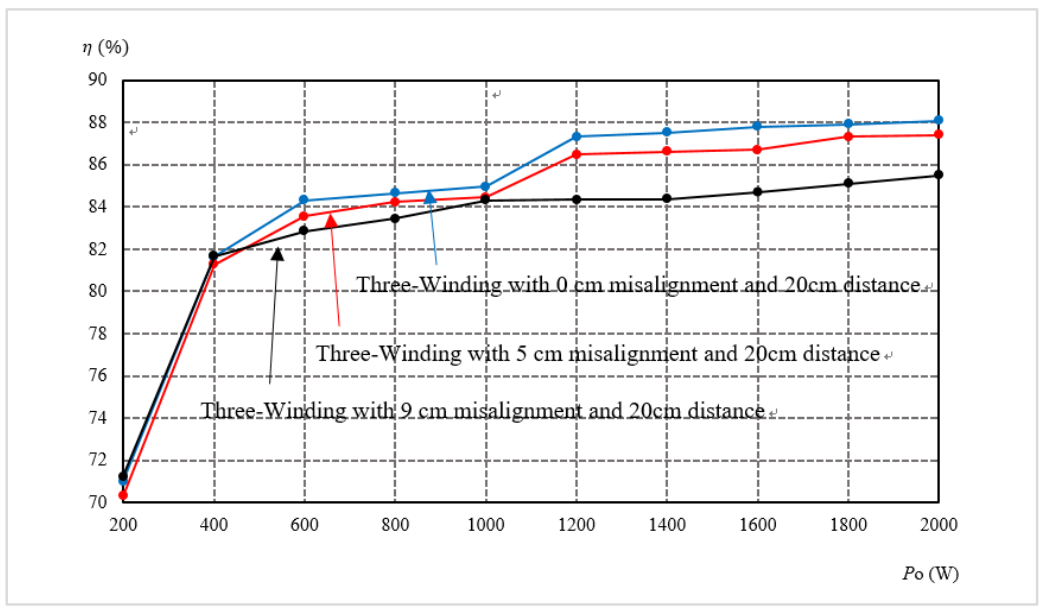

(b)

Figure 17. The measured efficiency of the three-winding IPT (a) without misalignment, (b) with misalignment.

\section{Conclusions}

In this paper, a three-winding IPT system is investigated, and a method to calculate the efficiency of the proposed IPT is developed. From experimental results, the proposed IPT system achieves $88 \%$ efficiency at $2 \mathrm{~kW}$ with a $20 \mathrm{~cm}$ air gap. In addition, a detailed design and implementation of a predictive current-loop controller and predictive voltageloop controller to improve the dynamic responses of the IPT system, including transient responses, misalignment responses, and load disturbance responses are proposed here for the first time. Measured results show that the predictive controllers in our study have better performance than PI controllers. Moreover, several experimental results also demonstrate that the proposed IPT system works well, even though a $9 \mathrm{~cm}$ misalignment occurs. The experimental results match the simulated results well.

Author Contributions: Conceptualization, T.-H.L.; methodology, T.-H.L.; validation, Z.-J.L.; resources, T.-H.L.; writing-original draft preparation, T.-H.L. and M.S.M.; writing-review and editing, T.-H.L. and M.S.M.; supervision, T.-H.L.; funding acquisition, T.-H.L. All authors have read and agreed the published version of the manuscript.

Funding: This research was funded by Ministry of Science and Technology Taiwan. Grant number MOST 109-2221-E-011-050.

Data Availability Statement: Data sharing not applicable.

Acknowledgments: The paper was supported by MOST, Taiwan, under Grant MOST 108-2221-E011-085 and -086.

Conflicts of Interest: The authors declare no conflict of interest.

\section{References}

1. Chen, Y.; Mai, R.; Zhang, Y.; Li, M.; He, Z. Improving misalignment tolerance for IPT system using a third-coil. IEEE Trans. Power Electron. 2019, 34, 3009-3013. [CrossRef]

2. Shevchenko, V.; Husev, O.; Strzelecki, R.; Pakhaliuk, B.; Poliakov, N.; Strzelecka, N. Compensation topologies in IPT systems: Standards, requirements, classifications, analysis, comparison and application. IEEE Access 2019, 7, 120559-120580. [CrossRef]

3. Hao, H.; Covic, G.A.; Boys, J.T. An approximate dynamic model of LCL-T-based inductive power transfer power supplies. IEEE Trans. Power Electron. 2014, 29, 5554-5567. [CrossRef]

4. Li, Y.; Du, H.; He, Z.; Zhou, W. Robust control for the IPT system with parametric uncertainty using LMI pole constraints. IEEE Trans. Power Electron. 2020, 35, 1022-1035. [CrossRef]

5. Xia, C.; Sun, Q.; Li, X.; Hu, A.P. Robust $\mu$-synthesis control of dual LCL type IPT System considering load and mutual inductance uncertainty. IEEE Access 2019, 7, 72770-72782. [CrossRef]

6. Li, Y.; Du, H.; Yang, M.; He, Z. Two-degree-of-freedom $H^{\infty}$ robust control optimization for the IPT system with parameter perturbations. IEEE Trans. Power Electron. 2018, 33, 10954-10969. [CrossRef] 
7. Nail, B.; Bekhiti, B. Optimal static state-feedback controller design for multivariable bidirectional IPT system using block roots and Harris Hawks optimizer. In Proceedings of the IEEE ICSRESA-2019, Tebessa, Algeria, 4-5 December 2019; pp. 1-6.

8. Rodriguez, J.; Cortes, P. Predictive Control of Power Converters and Electrical Drives; John Wiley \& Sons, Ltd.: West Sussex, UK, 2021.

9. Wang, L.; Chai, S.; Yoo, D.; Gan, L.; Ng, K. PID and Predictive Control of Electrical Drives and Power Converters using MATLAB/Simulink; John Wiley \& Sons, Ltd.: Singapore, 2015.

10. Winders, J.J. Power Transformer-Principles and Applications; Marcel Dekker: New York, NY, USA, 2002.

11. Ding, B.C. Modern Predictive Control; CRC Press: New York, NY, USA, 2010.

12. Maciejowski, J.M. Predictive Control. with Constraints; Prentice Hall: London, UK, 2002.

13. Wang, L. Modern Predictive Control. System Design and Implementation Using MATLAB; Springer: Berlin/Heidelberg, Germany, 2009. 